\title{
The Study of Mathematical Modelling Thinking Method in Mathematics Teaching in Colleges and Universities
}

\author{
Shengguang Peng \\ Pingxiang University, Jiangxi 337055, China
}

Keywords: mathematical modelling, university mathematics, innovative thinking.

\begin{abstract}
With the continuous development of science and technology, mathematics has applied in the various fields of science in our country, especially in engineering and economics management. Mathematics is the foundation of the nine-year compulsory education in our country, and occupies a large proportion in the quality education. Therefore, mathematical learning is very important for college students of engineering. In order to facilitate the mathematics learning of college students, simplify the abstruse mathematical matters, and integrate the mathematical modelling thought with the teaching of college mathematics course, the model of teaching method can effectively improve the efficiency of mathematics teacher's teaching, stimulate students' interest in learning of mathematics. The paper discusses the role of mathematical modelling ideas in students' mathematics learning, and how to integrate the ideas of mathematical modelling with the mathematics learning method in colleges, so as to promote the reform of college mathematics.
\end{abstract}

\section{Introduction}

With the continuous development of China's science and technology, computer application technology brought unprecedented convenience to our life, mathematics application in our daily life is becoming more and more common, use mathematical method to solve the difficult problems in our life and work will become the development trend of mathematics application in the future. University mathematics teaching efficiency depends largely on the students interest in learning of mathematics, to apply mathematical modelling ideas in mathematics teaching mathematical problems can be visual, simple, will be boring mathematics classroom to become more lively and interesting, so as to inspire the students' learning efficiency, improve the quality of mathematics teaching.

\section{A summary of the application of mathematical model}

Along with the socialist economic development, mathematics has been widely used in different fields, set up mathematical model to solve the problem of the practical work is a college student community is often used in basic skills. By using mathematical model to solve the problem is only with mathematics knowledge and mathematics problem-solving ability is not enough, it also needs to comprehensive quality and ability of college students has the good, and the excellent quality of professional talents in the social work is much more popular than the mathematics specialized personnel. Of institutions of higher learning education goal is to provide production, service and management of the front of high-quality professional talents, so the application of mathematical modelling became a college mathematics specialized students' essential qualities and skills.

\section{Disadvantages of mathematics teaching in colleges and universities}

Mathematics as a tool, the basis of scientific research in terms of knowledge talent cultivation has an irreplaceable role, but the current mathematics teaching in colleges and universities on the teaching contents and teaching methods there are certain drawbacks. From the teaching content of the university mathematics, the teacher emphasizes the theoretical education and ignores the 
practical application of mathematics. Focusing too much on solving mathematical problems and ignoring the whole train of thought; it is too important to emphasize the classics of the case, but to ignore the introduction of new cases, and not to exercise new thinking. On the teaching methods of it, the math teacher often takes the imparting of knowledge and ignore the study method of instruction to the student, makes the students cannot independent solve the problem, the lack of independent thinking ability, as long as a meets the actual problem, students tend to appear, I don't know where to begin. Practice investigation proves that the mathematics education in colleges and universities introduced in mathematical modelling thought and teaching method, can obtain good teaching effect, many students gradually in the process of establishing mathematical model for the professional developed an interest in maths, the introduction of mathematical modelling thought promoted the students to combine theoretical knowledge with social practice mode of learning, make students' learning efficiency has improved significantly.

\section{The role of mathematical modelling ideas and methods in the teaching of mathematics in universities}

Mathematical modelling is to use mathematical language and methods to translate realistic information and to collect and summarize the resulting mathematical products. Mathematical model after deduction and inference and the solving process, finally to draw inferences and practice carried out to verify the results back to the social reality of world, and complete mathematical model from practice to theory, from theory to practice effective cycle again. From the point of view of mathematics teaching, guide students by using the mathematical knowledge learned mathematical model is an innovative method of study, the use of this method can let students experience the integrated use of the process of mathematics knowledge and methods to solve practical problems, can effectively stimulate students' learning enthusiasm, helps to cultivate students' innovation consciousness and improve students' comprehensive ability to use math.

\subsection{The idea of mathematical modelling is conducive to stimulating students' interest in learning}

The thought process of mathematical modelling conforms to the development rules of students' cognitive processes of things, and mathematical modelling can effectively improve students' learning mathematics and apply the enthusiasm of mathematics. Mathematical modelling from practice to theory and practice of building process, not only can help students to firmly grasp mathematics knowledge, also can effectively train students' ability of using mathematical language and mathematical method, help students set up the correct view of mathematics, and effectively promote the students' consciousness of using mathematics in their life. Mathematical modelling to the vivid image of the boring mathematical theoretical knowledge into the reality of the case, make the student feel very clear in the process of mathematics application in daily life, can effectively inspire the students mathematical, improve the students' learning efficiency. The formation of mathematical modelling ideas can make students have good learning habits in their study, even in the future work and life.

\subsection{The idea of mathematical modelling can help students cultivate the consciousness of innovation}

Traditional teaching concept focuses on teachers in a leading role in the process of teaching, the teacher to the student blindly for imparting theoretical knowledge, the students as the storage of knowledge, too much focus on knowledge, little time left for students' thinking in class, thus inhibiting the development of students' creative thinking ability. The traditional education mode of mathematics focuses on the interpretation of mathematical knowledge, and the mathematical induction method is not too important. Although the deductive method in mathematics learning is very important, is helpful for students to study and application of the principle of mathematics, but it's for the formation of students' innovative thinking consciousness without too much help, not a good guide students to innovate. In order to cultivate students' innovative thinking in mathematics, 
we must pay attention to the study of induction in mathematics, and cultivate students' ability to find and generalize from social reality. Therefore, the university mathematics teacher should transform education idea and innovate education idea, introduce mathematical modelling thought in mathematics class, which is beneficial to improve students' innovation ability.

\subsection{The thought of mathematical modelling can help improve students' ability of mathematical application}

Use mathematical model to solve practical problems, not only the need of what they have learned in the university mathematics knowledge, but also needs the comprehensive knowledge of many sided, including skilled in computer application technology and the problem of modelling capabilities. Teacher to train students' ability of mathematical modelling to make students master the mathematical background of knowledge, and deepen to the deep understanding of the problem and develop students' knowledge, improve the level of students' mathematics knowledge from various respects.

\section{Specific methods and measures of mathematical modelling applied in mathematics teaching}

Introducing mathematical modelling ideas in mathematics teaching need to instance as the center, let the students master the mathematical modelling in the process of learning experience and the center of the step, the teacher should be enriched the contents of the mathematics classroom teaching and the students as the main body, heuristic teaching, practice teaching is the combination of various forms of teaching pattern, fully let students experience the whole process of using mathematical knowledge to solve practical problems, and experience the fun of learning.

\subsection{Start learning from the application of the example}

Students of mathematics learning not only confined to the concept of mathematics, problem solving method and the conclusion of study, but more should study mathematics thought method, grasp the spiritual essence of mathematics, and understand the sources and application of mathematics, fully accept the mathematics culture. In order to achieve the teaching purpose, the math teacher should combine the teaching curriculum, let the students to realize what they learn at ordinary times dull teaching concept, theorem and formula not unfounded, and from the practical problems through summary, induction, reasoning has scientific basis of intellectual achievements. The instance is introduced into classroom teaching, from teaching achievements, mathematical modelling thought can fully to let students understand mathematical theory comes from practice, and the ultimate goal of learning mathematics is to apply mathematical theory to return to real life, students understand the practical significance of the study mathematics, help to improve learning interest in mathematics, to promote the cultivation of innovative consciousness.

\subsection{Verify the mathematical theorem in real life}

Many of the theorems in college mathematics textbooks are abstracted from practical problems, but it is because the theorems and formulas are so abstract that students are very boring and boring in their studies. So the math teacher taught in theorem, the first to combine the actual application of mathematical theorems about the interpretation of, let the students have an intuitive impression, and combining with the ideas and methods of mathematical modelling, the conditions of theorem as model assumption, based on the previously set problem situation step by step guide the student to derive the final conclusion, students by using the theorem to solve practical problems and felt the theorem using the actual value. For example, the existence theorem of the zero existence of a function on the closed interval is very important in the study of higher mathematics. There are two main applications of the zero theorem: one is to verify the existence of other theorems, and the other is to verify whether the equation has roots on some interval. Students learn this theorem with the question that a theorem exists to validate another theorem, and that the theorem has no practical 
application value. So our university math teacher, after the proof of the theorem, had better be able to combine real life problems to verify the actual application of the theorem.

\subsection{Strengthen the sense of application by combining the subject matter}

Mathematics learning involves each professional colleges, electronic technology professional, for one, graduates is mainly engaged in the engineering and scientific job after graduation, the work requires students to have math skills and the ability to solve the problem of science. The purpose of students' learning mathematics is primarily in order to develop mathematical thinking ability to analyze the problem and solve the specific problems in work ability, the professional demands for college students to understand the importance of mathematical thinking and using mathematics. Therefore in mathematics teaching in university teacher requires a combination of professional knowledge, according to the different targeted to choose typical problems of professional teaching, remove the some cases of pure mathematics, the mathematical teaching material can effectively arouse the students' thirst for knowledge, to strengthen the mathematical thinking in the process of mathematical modelling and mathematical application consciousness, improve the professional ability of students.

\section{Conclusion}

Above all, in mathematics teaching in university through mathematical modelling thought, equal to impart to students a good learning method, especially for the students to set up a bridge from the mathematics knowledge to the practical problems, students only have a lot of contact with reality examples related to the professional, to establish a correct concept of mathematics, improve the overall effect of mathematics classroom teaching, broaden the students to solve the problem, improve the students' ability to analyze and solve practical problems, to strengthen the professional knowledge, improve the talent training, carries high quality talents for the society from all walks of life.

\section{References}

[1] Chen long. The research on the application of mathematical modelling ideas in higher mathematics teaching [J]. Asia-pacific education, 2016 (4).

[2] Liu jun. Integration of mathematical modelling ideas in advanced mathematics teaching [J]. Science and technology horizon, 2016 (5).

[3] Lin xianning. The research of mathematical modelling in higher vocational mathematics [J]. Information construction, 2015 (12). 